\title{
Performance luminosa da associação entre elemento vazado, janela alta e prateleira de luz
}

Luminic performance of the association between perforated solar screen, high window and light shelf

Actuación luminosa de la asociación entre pantalla solar perforada, ventana alta y estante de luz

Recebido em 14/08/2020 Aceito em 21/04/2021

BOLSSONI, Gabriela da Conceição ${ }^{1}$ LARANJA, Andréa Coelho ${ }^{2}$

Universidade Federal do Espírito, Faculdade de Arquitetura e Urbanismo, Programa de Pós-Graduação em Arquitetura e Urbanismo.Vitória, Espírito Santo, Brasil.

1gabriela_bolssoni@hotmail.com ORCID: 0000-0002-4337-1712

2andreacoelholaranja@gmail.com ORCID: 0000-0001-6729-0653 


\title{
Resumo
}

Esta pesquisa teve como objetivo investigar a performance luminosa da associação entre elemento vazado, janela alta e prateleira de luz para um ambiente interno de escritório em localidade de clima tropical úmido. $\mathrm{Na}$ metodologia foram feitas modelagens com o Rhinoceros3D+Grasshopper e simulações com o DIVA-for-Rhino. Como parâmetros de análises adotou-se os intervalos da UDI (Useful Daylight Illuminances), a Autonomia da lluminação Natural (DA) e a Uniformidade. As avaliações foram feitas para Norte e Oeste para os seguintes modelos: Modelo I (elemento vazado), Modelo II (elemento vazado + janela alta) e Modelo III (elemento vazado + janela alta + prateleira de luz). Utilizando como base o Modelo III foram avaliados mais quatro modelos variando a profundidade interna da prateleira de luz. Os resultados apontaram a dificuldade de os modelos alcançarem os limites mínimos de DA $(500 \mathrm{~lx})$ e de Uniformidade $(0,6)$, indicando tanto a necessidade de acionamento da iluminação artificial como a existência de elevados contrastes luminosos. O Modelo III10 para Norte e o Modelo III30 para Oeste obtiveram a melhor performance em relação à UDI, garantindo iluminação adequada em cerca de $70 \%$ das horas, iluminando de maneira mais eficiente a região profunda do ambiente e admitindo baixos percentuais de iluminação excessiva.

Palavras-Chave: desempenho lumínico, elementos vazados, janela alta, prateleira de luz, simulação computacional.

\begin{abstract}
This research aimed to investigate the luminous performance of the association between perforated solar screen, high window and light shelf for an indoor office environment in a humid tropical climate. In the methodology, modeling was done with Rhinoceros3D + Grasshopper and simulations with DIVA-forRhino. As analysis parameters, the UDI (Useful Daylight Illuminances) intervals, Daylight Autonomy (DA) and Uniformity were adopted. The evaluations were made for North and West for the following models: Model I (perforated solar screen), Model II (perforated solar screen + high window) and Model III (perforated solar screen + high window + light shelf). Using Model III as a base, four more models were evaluated, varying the internal depth of the light shelf. The results point to the difficulty of the models reaching the minimum limits of DA $(500 / x)$ and Uniformity $(0,6)$, indicating both the need to activate artificial lighting and the existence of high luminics contrasts. The Model III10 to the North and the Model III30 to the West achieved the best performance in relation to the UDI, ensuring adequate lighting in about $70 \%$ of the hours, more efficiently lighting the deep region of the environment and admitting low percentages of excessive lighting.
\end{abstract}

Key-Words: daylighting performance, perforated solar screen, high window, light shelf, computacional simulation.

\section{Resumen}

Esta investigación tuvo como objetivo investigar el actuación luminosa de la asociación entre pantalla solar perforada, ventana alta y estante de luz para un ambiente interior de oficina en un clima tropical húmedo. En la metodología se realizaron modelos con Rhinoceros3D + Grasshopper y simulaciones con DIVA-for-Rhino. Como parámetros de análisis se adoptaron los intervalos UDI (Useful Daylight Illuminances), la Autonomía de Luz Natural (DA) y la Uniformidad. Las evaluaciones se realizaron para Norte y Oeste para los siguientes modelos: Modelo I (pantalla solar perforada), Modelo II (pantalla solar perforada + ventana alta) y Modelo III (pantalla solar perforada + ventana alta + estante de luz). Usando el Modelo III como base, se evaluaron cuatro modelos más, variando la profundidad interna del estante de luz. Los resultados apuntan a la dificultad de los modelos para alcanzar los límites mínimos de DA (500lx) y Uniformidad (0,6), lo que indica tanto la necesidad de activar la iluminación artificial como la existencia de altos contrastes lumínicos. El Modelo III10 al Norte y el Modelo III30 al Oeste lograron el mejor desempeño en relación al UDI, asegurando una iluminación adecuada en aproximadamente el $70 \%$ de las horas, iluminando de manera más eficiente la región profunda del ambiente y admitiendo bajos porcentajes de iluminación excesiva.

Palabras clave: actuación luminosa, pantalla solar perforada, ventana alta, estante de luz, simulación computacional. 


\section{Introdução}

A luz natural é uma fonte renovável, gratuita e abundante no território brasileiro e quando corretamente captada e distribuída pode auxiliar na redução do consumo de energia elétrica (MESA; CORICA; PATTINI, 2011; RAPHAEL, 2011; LAMBERTS; DUTRA; PEREIRA, 2014). Além das vantagens econômicas, a luz natural propícia um ambiente mais agradável, garantindo ainda melhores condições de saúde, pois exerce influência importante no ciclo biológico dos seres humanos (MARTAU, 2009; FIGUEIRÓ, 2010; SANTOS, 2014). No entanto, a alta luminosidade admitida por aberturas sem sombreamento pode ocasionar ganhos térmicos e desconforto visual decorrente do brilho intenso (FREEWAN, 2014; MAIOLI, 2014).

Dentre os dispositivos capazes de proporcionar sombreamento evidenciam-se os elementos vazados. Esses são definidos por Ching (2010) como qualquer sistema de vedação que inclua o espaço vazio, ou seja, que não seja maciço em toda a sua superfície. Cartana; Pereira e Meyer (2018) identificaram que o emprego de elementos vazados contribui no controle da admissão de radiação solar, na melhor distribuição da luz natural e na redução do ofuscamento. No entanto, Bolssoni e Laranja (2019a) constataram que apesar de os elementos vazados serem eficientes na redução da iluminação excessiva nos trechos mais próximos à fachada, esses foram incapazes de iluminar de maneira adequada ambientes internos profundos. Nesse sentido, vale mencionar as janelas altas como um recurso capaz de alcançar os trechos mais profundos dos ambientes, garantindo uma distribuição da luz de maneira mais uniforme (GONÇALVES; VIANA; MOURA, 2011).

Um outro artefato capaz de proporcionar sombreamento diz respeito à prateleira de luz. Trata-se de uma estrutura horizontal posicionada acima do campo de visão, podendo ser externa, interna ou ambos (BAKER; FANCHIOTTI; STEEMERS, 2010). A função da prateleira de luz é bloquear a radiação solar direta que penetra o ambiente através da janela ao mesmo tempo que redireciona a luz que atinge sua superfície superior para o teto, o qual refletirá a luz para trechos maios profundos do ambiente, auxiliando na uniformização da iluminância (FREEWAN, 2010). Entretanto, Ochoa e Capeluto (2006) advertem que há controvérsias quanto a capacidade da prateleira de luz de iluminar regiões profundas do ambiente interno.

Diante do exposto, este artigo teve como objetivo investigar a performance luminosa da associação entre elemento vazado, janela alta e prateleira de luz para um ambiente interno de escritório em localidade de clima tropical úmido.

\section{Metodologia}

A metodologia foi organizada segundo as etapas a seguir: (1) Caracterização do Ambiente Interno; (2) Modelagem Paramétrica e Simulações Computacionais; (3) Caracterização dos Modelos Simulados.

\subsection{Caracterização do Ambiente Interno}

Para definição da geometria do ambiente interno utilizou-se uma sala hipotética de escritório situada em Vitória - ES (20¹9'15" latitude Sul e 40²0'10" longitude Oeste). Para reproduzir as características do clima de Vitória - ES, foi utilizado o arquivo climático da cidade de Vitória - ES (Vitória TRY1962_05CSV.epw, disponível em: http://www.labeee.ufsc.br/downloads/arquivosclimaticos/formato-try-swera-csv-bin). As avaliações foram feitas para as orientações Norte e Oeste por serem as orientações que recebem a maior radiação solar para a localidade de Vitória - ES, demandando dessa forma elementos sombreadores.

A geometria da sala obedece às diretrizes do Código de Obras de Vitória (1998), tem dimensões que se aproximam dos modelos reais de escritório construídos em Vitória e, por fim, atende uma relação de proporcionalidade entre os lados descrita por Lamberts; Ghisi; Ramos (2006). 
A Tabela 1 traz as dimensões do ambiente interno adotado para as avaliações e a verificação em relação aos requisitos do Código de Obras de Vitória (1998).

Tabela 1: Verificação dos parâmetros adotados em função dos requisitos indicados pelo Código de Obras

\begin{tabular}{ccc}
\hline Dimensão & $\begin{array}{c}\text { Requisitos do Código de } \\
\text { Obras }\end{array}$ & $\begin{array}{c}\text { Dimensões do ambiente } \\
\text { adotado }\end{array}$ \\
\hline Pé-direito $(\mathrm{Pd})$ & $\mathrm{Pd} \geq 2,60 \mathrm{~m}$ & $\mathrm{Pd}=2,60 \mathrm{~m}$ \\
\hline Largura $(\mathrm{L})$ & $\mathrm{L} \geq 2,00 \mathrm{~m}$ & $\mathrm{~L}=4,00 \mathrm{~m}$ \\
\hline Profundidade $(\mathrm{P})$ & $\mathrm{P} \leq 4 \times \mathrm{L}$ & $\mathrm{P}=8,00 \mathrm{~m}$ \\
\hline Área $(\mathrm{A})$ & $\mathrm{A} \geq 7,50 \mathrm{~m}^{2}$ & $\mathrm{~A}=32,00 \mathrm{~m}^{2}$ \\
\hline Fonte: elaborado pelas autoras com base no Código de Obras de Vitória (1998)
\end{tabular}

A Figura 1, abaixo, apresenta perspectivas com as dimensões do ambiente interno adotado para as avaliações.

Figura 1: Perspectivas do ambiente interno com as dimensões adotadas para as avaliações
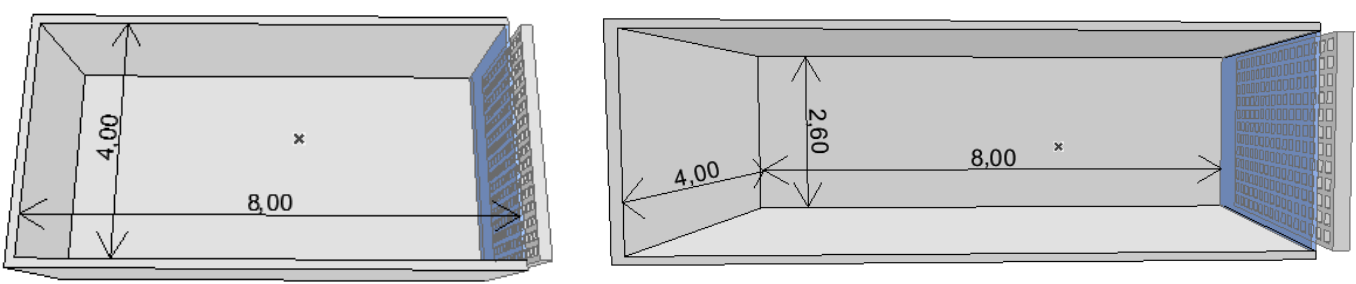

Fonte: autoras

No que se refere as refletâncias das superfícies do ambiente interno (piso, parede e teto) essas foram definidas com base nas refletâncias internas sugeridas pela NBR ISO/CIE 8995 (ABNT, 2013), como indica a Tabela 2.

Tabela 2: Refletância recomendada pela NBR ISO CIE 8995 (ABNT, 2013) para as superfícies e refletância utilizada

\begin{tabular}{ccc}
\hline Superfícies & $\begin{array}{c}\text { Refletância recomendada (\%) } \\
\text { NBR ISO/CIE 8995 }\end{array}$ & Refletância utilizada (\%) \\
\hline Piso & $10-50$ & 20 \\
\hline Parede & $30-80$ & 60 \\
\hline Teto & $60-90$ & 80 \\
\hline \multicolumn{2}{c}{ Fonte: elaborado pelas autoras com base na NBR ISO CIE 8995 (ABNT, 2013) }
\end{tabular}

Em relação ao vidro utilizado na fachada foi empregado vidro simples com $6 \mathrm{~mm}$ de espessura e fator de transmitância de $88 \%$.

\subsection{Modelagem Paramétrica e Simulações Computacionais}

Os modelos simulados foram desenvolvidos utilizando o Grasshopper, editor de algoritmos do software de modelagem Rhinoceros 3D, e as simulações computacionais relativas ao desempenho lumínico foram realizadas utilizando o plug-in DIVA-for-Rhino. O DIVA-for-Rhino é um plug-in de modelagem de energia e luz natural otimizado para o Rhinoceros. Dentre outras funções, o DIVA-for-Rhino permite avaliação de medidas dinâmicas de iluminação natural.

Nas simulações de desempenho lumínico buscou-se avaliar qual dos modelos é capaz de: garantir iluminação natural satisfatória, reduzir os contrastes luminosos e proporcionar uma distribuição da luz mais uniforme. Para tanto, foi feita análise das iluminâncias com base nos intervalos da UDI (Useful Daylight Illuminances) propostos por Nabil e Mardaljevic (2006). A UDI expressa a porcentagem de horas que cada ponto do ambiente analisado se encontra em cada um dos intervalos, sendo os seguintes os intervalos considerados: $E<1001 x$ - intervalo insuficiente, $1001 x \leq E<20001 x$ - intervalo recomendado e Eæ2000lx - intervalo excessivo. 
Outra medida dinâmica de iluminação natural que tem sido amplamente utilizada é a Daylight Autonomy (DA) ou Autonomia da lluminação Natural. Essa é definida como a porcentagem de horas ocupadas do ano onde um valor mínimo de iluminância é atingido (REINHART; WIENOLD, 2011). Todavia, diferente da UDI, a DA não estabelece um limite máximo de iluminância admissível, dificultando a indicação da possibilidade de desconforto visual dos ocupantes (NABIL; MARDALJEVIC, 2006). Ainda nesse sentido, Maioli (2014) atenta que altos valores de DA podem mascarar índices considerados excessivos de iluminância no ambiente, contribuindo para a redução do percentual de horas anuais presentes no intervalo de iluminância útil.

Para determinar o valor da DA utilizou-se como base a NBR ISO/CIE 8995-1 (ABNT, 2013), que determina a iluminância adequada para cada tipo de atividade desenvolvida em diversos ambientes, como indica a Tabela 3 para as atividades de escritório.

Tabela 3: lluminância indicada pela NBR ISO/CIE 8995-1 (ABNT, 2013) para atividades de ambiente de escritório

\begin{tabular}{lc}
\hline \multicolumn{1}{c}{ Atividades de Escritório } & E (Iux) \\
\hline Arquivamento, cópia, circulação, etc. & 300 \\
\hline Escrever, teclar, ler, processar dados & 500 \\
\hline Desenho técnico & 750 \\
\hline Estações de projeto assistido por computador & 500 \\
\hline Salas de reunião e conferência & 500 \\
\hline Recepção & 300 \\
\hline Arquivos & 200 \\
\hline Fonte: elaborado pelas autoras com base na NBR ISO/CIE 8995-1 (ABNT, 2013)
\end{tabular}

Conforme observado na Tabela 3, atividades comumente desenvolvidas em escritórios, como escrever, teclar, ler, desenvolver projetos assistidos por computador e ministrar conferência requerem iluminância de 500 lux, esse então adotado como referência para a DA.

A NBR ISO/CIE 8995-1 (ABNT, 2013) determina ainda o valor de Uniformidade apropriado para o ambiente interno. A Uniformidade $(U)$ é determinada pela razão entre o valor de iluminância mínimo (Emin) e o valor de iluminância médio (Emed), como indica a Equação 1, adotando-se como base a Uniformidade mínima a ser alcançada de 0,6 (ABNT, 2013) em função do layout flexível das salas de escritório.

$U=\frac{E m i ́ n}{E m e ́ d}$

Para todas as avaliações de desempenho lumínico (UDI, DA e Uniformidade) adotou-se um plano horizontal de análise à $75 \mathrm{~cm}$ de altura, com sensores espaçados ortogonalmente em $50 \mathrm{~cm}$ entre si, como indica a NBR 15215-4 (ABNT, 2005), estando 8 sensores dispostos no eixo X e 16 sensores dispostos no eixo $\mathrm{Y}$, totalizando 128 sensores, como demonstra a Figura 2.

Figura 2: Posicionamento dos sensores de avaliação do desempenho lumínico

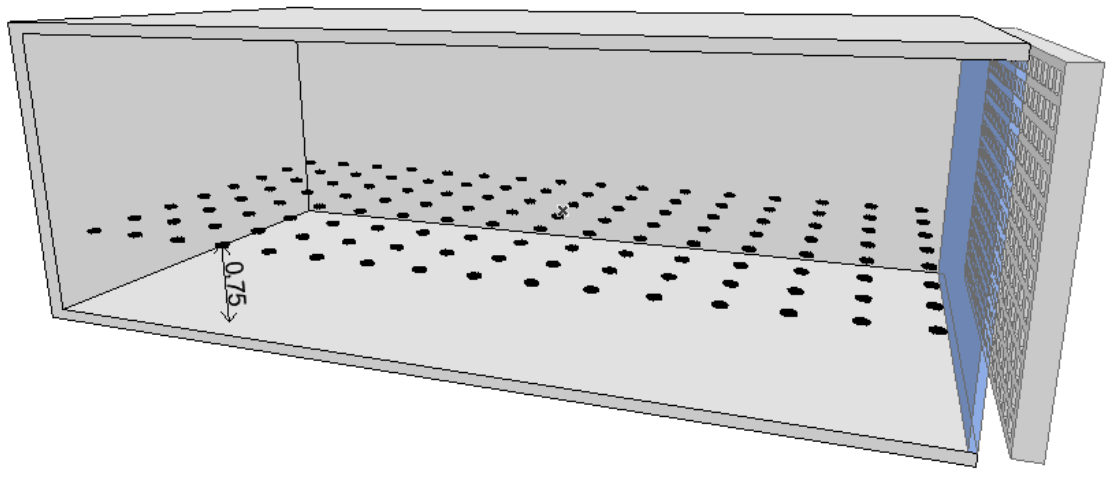

Fonte: autoras 
No que se refere ao período das simulações computacionais, em relação à UDI e à DA foram realizadas avaliações para todos os dias do ano no horário de $8 \mathrm{~h}$ às $18 \mathrm{~h}$, conforme o período de ocupação do ambiente analisado. Enquanto para a avaliação da Uniformidade, foram realizadas simulações para solstícios de inverno e verão (21 de junho e 21 de dezembro, respectivamente), a cada duas horas, como indica a NBR 15215-4 (ABNT, 2005), para os horários das 8h, 10h, 12h, 14h e $16 \mathrm{~h}$.

\subsection{Caracterização dos Modelos Simulados}

Inicialmente foram feitas avaliações para os intervalos da UDI que se deu em duas etapas, os modelos avaliados em cada uma dessas etapas são apresentados a seguir.

Na primeira etapa foram avaliados três modelos: Modelo I (elemento vazado); Modelo II (elemento vazado + janela alta); Modelo III (elemento vazado + janela alta + prateleira de luz). O elemento vazado que compõe todos os modelos dista $20 \mathrm{~cm}$ da fachada envidraçada, funcionando como uma segunda pele. Esse possui furos quadrados com dimensão de $14,5 \times 14,5 \mathrm{~cm}$ com área total de abertura que atende ao mínimo admitido pelo Código de Obras de Vitória (1998) e espessura de $20 \mathrm{~cm}$ que resulta em ângulos de insolação de $36^{\circ}$. A Figura 3 apresenta perspectivas, cortes esquemáticos e demais características dos modelos avaliados na primeira etapa.

Figura 3: Descrição, perspectivas e cortes esquemáticos dos Modelos I, II e III

\section{MODELO I}

Elemento vazado: dimensões de $4,0 \mathrm{~m}$ de largura $\times 2,60 \mathrm{~m}$ de altura, perfazendo toda a área de fachada $\left(10,40 \mathrm{~m}^{2}\right)$ e matriz de furos:16 furos no eixo $X$ e 12 furos no eixo $\mathrm{Y}$, totalizando 192 furos, com área total de abertura na fachada de $4 \mathrm{~m}^{2}$.

\section{MODELO ॥}

Elemento vazado: dimensões de 4,0m de largura $\times 2,16 \mathrm{~m}$ de altura, perfazendo uma área de $8,64 \mathrm{~m}^{2}$ e matriz de furos de 16 furos no eixo $X$ e 10 furos no eixo $Y$, totalizando 160 furos, com área total de abertura na fachada de $5,08 \mathrm{~m}^{2}$.
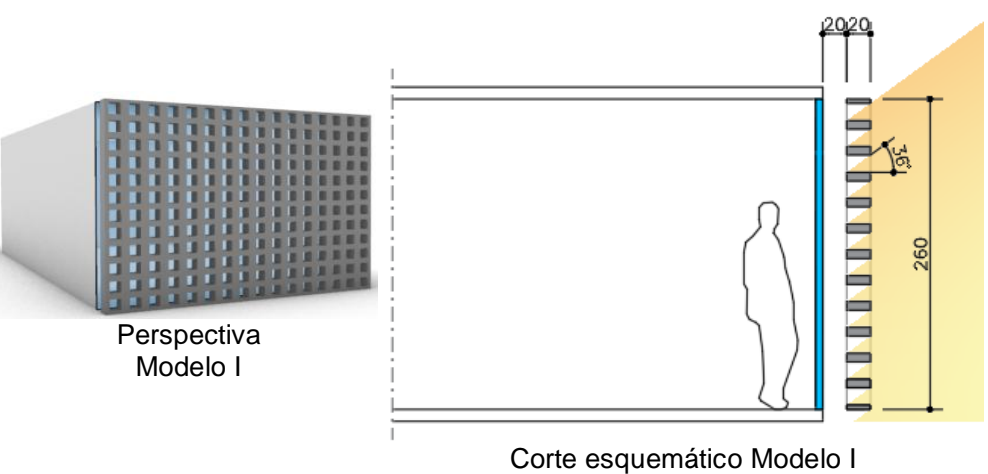

Corte esquemático Modelo
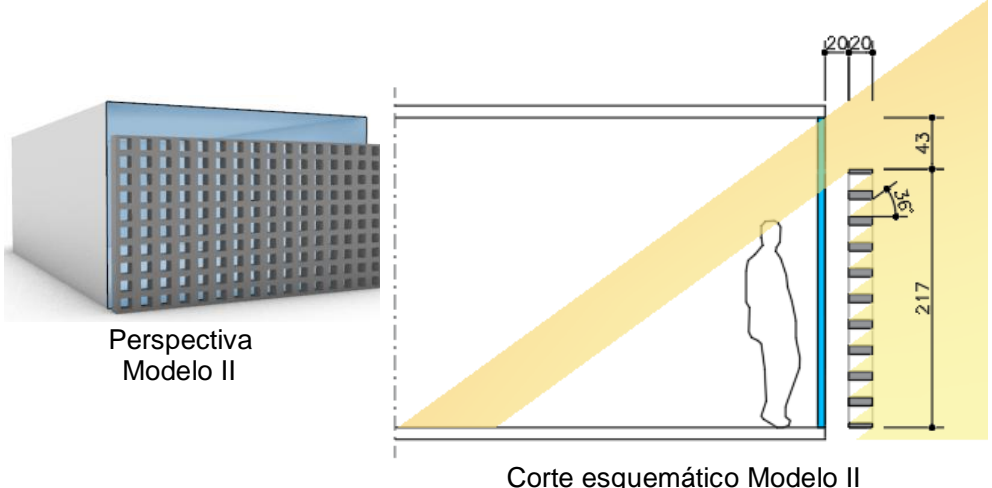

\section{MODELO III}

Elemento vazado: dimensões de 4,0m de largura $\times 2,16 \mathrm{~m}$ de altura, perfazendo uma área de $8,64 \mathrm{~m}^{2}$ e matriz de furos de16 furos no eixo $X$ e 10 furos no eixo $Y$, totalizando 160 furos, com área total de abertura na fachada de $5,08 \mathrm{~m}^{2}$.

Prateleira de luz: ângulo de insolação também de $36^{\circ}$ (mesmo do elemento vazado), que resulta na profundidade interna de aproximadamente $54 \mathrm{~cm}$.
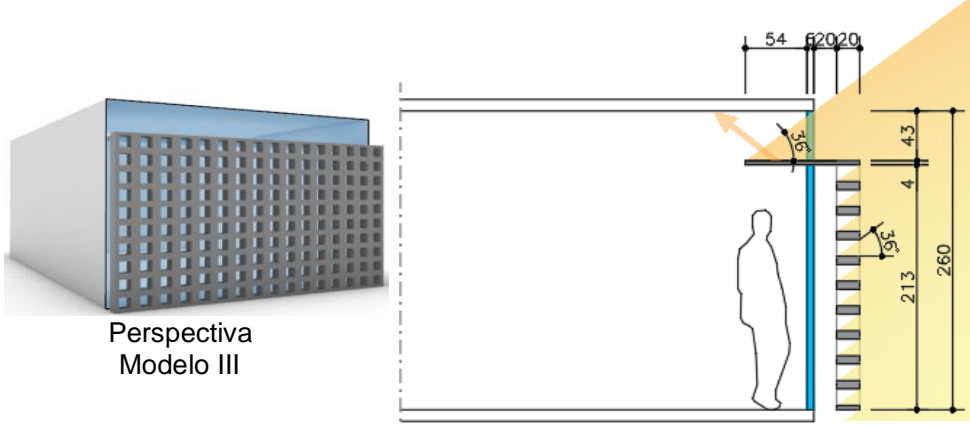

Corte esquemático Modelo II

Fonte: autoras 
$\mathrm{Na}$ segunda etapa de simulação utilizando-se como base o Modelo III (elemento vazado + janela alta + prateleira de luz), que obteve a melhor desempenho na primeira etapa, foram avaliadas mais quatro modelos variando a profundidade interna da prateleira de luz em $20 \mathrm{~cm}$ : Modelo III10, Modelo III 30 , Modelo III50 e Modelo III70, conforme ilustra a Figura 4.

Figura 4: Descrição e cortes esquemáticos dos Modelos III10, III30, III50 e III70

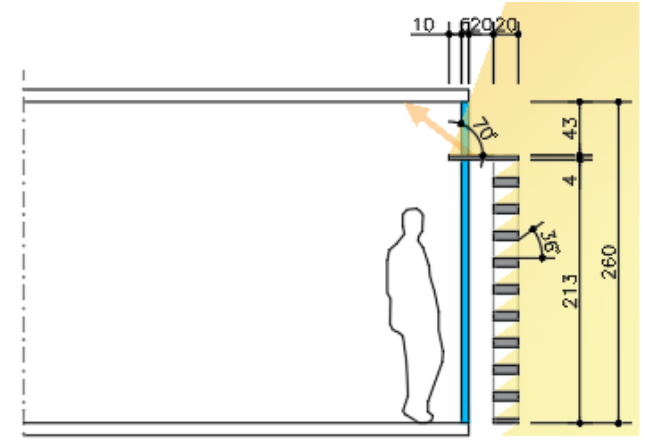

Modelo III10: prateleira de luz com profundidade interna de $10 \mathrm{~cm}$ e ângulo de insolação de $70^{\circ}$.

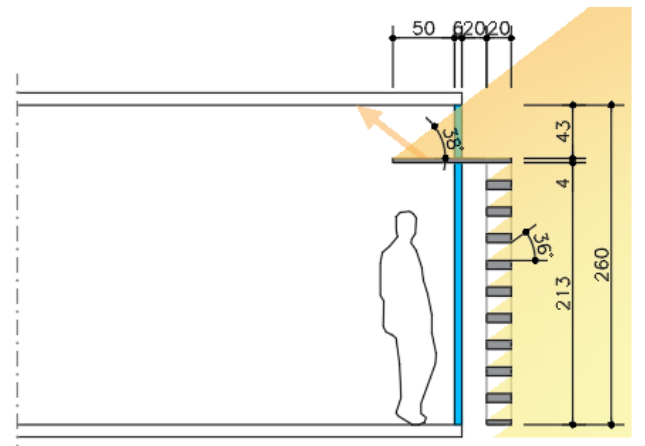

Modelo III50: prateleira de luz com profundidade interna de $\mathbf{5 0} \mathbf{c m}$ e ângulo de insolação de $38^{\circ}$.

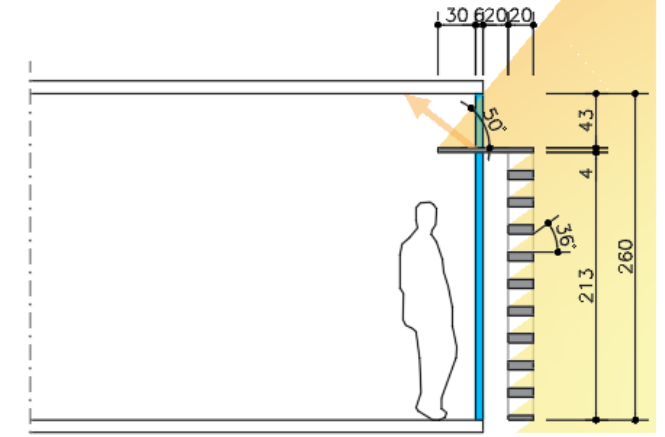

Modelo III30: prateleira de luz com profundidade interna de $30 \mathrm{~cm}$ e ângulo de insolação de $50^{\circ}$.

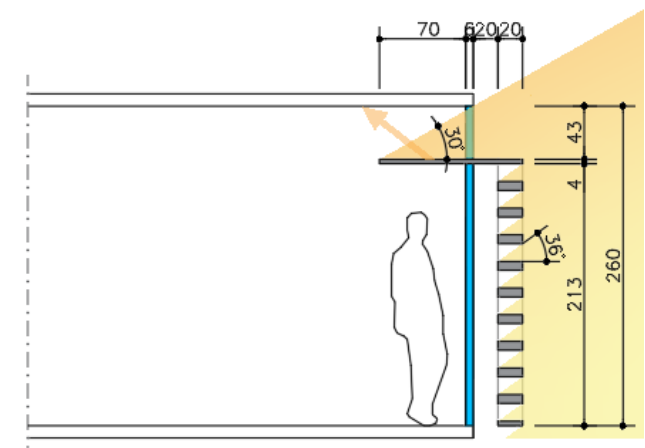

Modelo III70: prateleira de luz com profundidade interna de $\mathbf{7 0} \mathrm{cm}$ e ângulo de insolação de $30^{\circ}$.

Fonte: autoras

Para todos os modelos avaliados foi adotada a refletância de $80 \%$ para o elemento vazado, como indicado por Bolssoni e Laranja (2019) e para as prateleiras de luz.

De maneira complementar as avaliações dos intervalos da UDI, foram feitas análises relativas à Autonomia da Iluminação Natural (DA) e à Uniformidade para todos os modelos apresentados anteriormente.

\section{Resultados}

Os resultados foram organizados em três etapas conforme os parâmetros de avaliação e uma última etapa com a síntese dos resultados para todos os modelos e parâmetros avaliados, como descrito a seguir: (1) Intervalos da UDI (Useful Daylight Illuminance); (2) Autonomia da lluminação Natural/Daylight Autonomy (DA); (3) Uniformidade; (4) Síntese dos Resultados.

Como mencionado, as avaliações dos intervalos da UDI foram feitas em duas etapas, onde na primeira etapa foram avaliados três modelos: Modelo I (elemento vazado), Modelo II (elemento vazado + janela alta) e Modelo III (elemento vazado + janela alta + prateleira de luz). Conforme o desempenho verificado nessa primeira etapa conduziu-se uma segunda etapa de avaliação, utilizando-se como base o Modelo III, mas dessa vez explorando prateleiras de luz com profundidades diversas. Dessa forma, foram acrescidos mais quatro modelos: Modelo III10, Modelo III20, Modelo III30, Modelo III50 e Modelo 
III70. De maneira complementar, foram feitas análises para todos os modelos avaliados no que se refere à Autonomia da lluminação Natural (DA) e à Uniformidade.

\subsection{Intervalos da UDI (Useful Daylight IIluminance)}

Na primeira etapa de avaliação dos intervalos da UDI, para as orientações Norte e Oeste, como indica a Figura 5, para o intervalo insuficiente $(E<1001 x)$ observa-se que o Modelo II apresentou o melhor desempenho, ao compreender menos de $20 \%$ das horas do dia nesse intervalo, enquanto os demais apresentaram mais de 35\%. Isso indica um aumento no desempenho energético da edificação em função da menor demanda por energia elétrica para iluminação artificial.

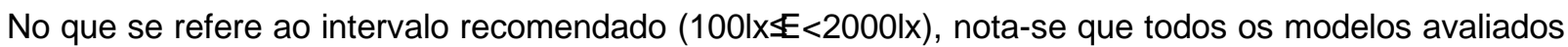
contemplaram mais de $50 \%$ das horas do dia nesse intervalo, destacando a melhor performance com o Modelo II onde somente em $30 \%$ das horas do dia será necessário o acionamento da iluminação artificial.

Em relação ao intervalo excessivo (Eæ2000lx), foi o Modelo III que apresentou o melhor desempenho ao reduzir de forma mais eficiente a iluminação excessiva, garantindo dessa forma menor ofuscamento e contraste lumininoso. Isso provavelmente decorrente da boa performance já conhecida da prateleira de luz em controlar a luz excessiva próximo da abertura e da janela alta de não deixar decair a luz nos trechos mais profundos do ambiente interno. Enquanto o pior desempenho se deu com o Modelo II que apresentou os maiores percentuais nesse intervalo.

De modo geral, apesar do Modelo II apresentar os maiores percentuais no intervalo recomendado (100|x $\leq<2000 \mid x)$, esse desempenho fica comprometido em função dos elevados percentuais também admitidos por esse modelo no intervalo excessivo, tendo em vista, que a iluminação excessiva está associada ao ofuscamento e ao ganho de calor. Sendo assim, a necessidade de controle dessa iluminação excessiva pelo usuário (acionamento de cortinas e persianas) acaba impossibilitando que esse usufrua da iluminação adequada.

Figura 5: Intervalos da UDI para os modelos avaliados na primeira etapa, orientações Norte e Oeste

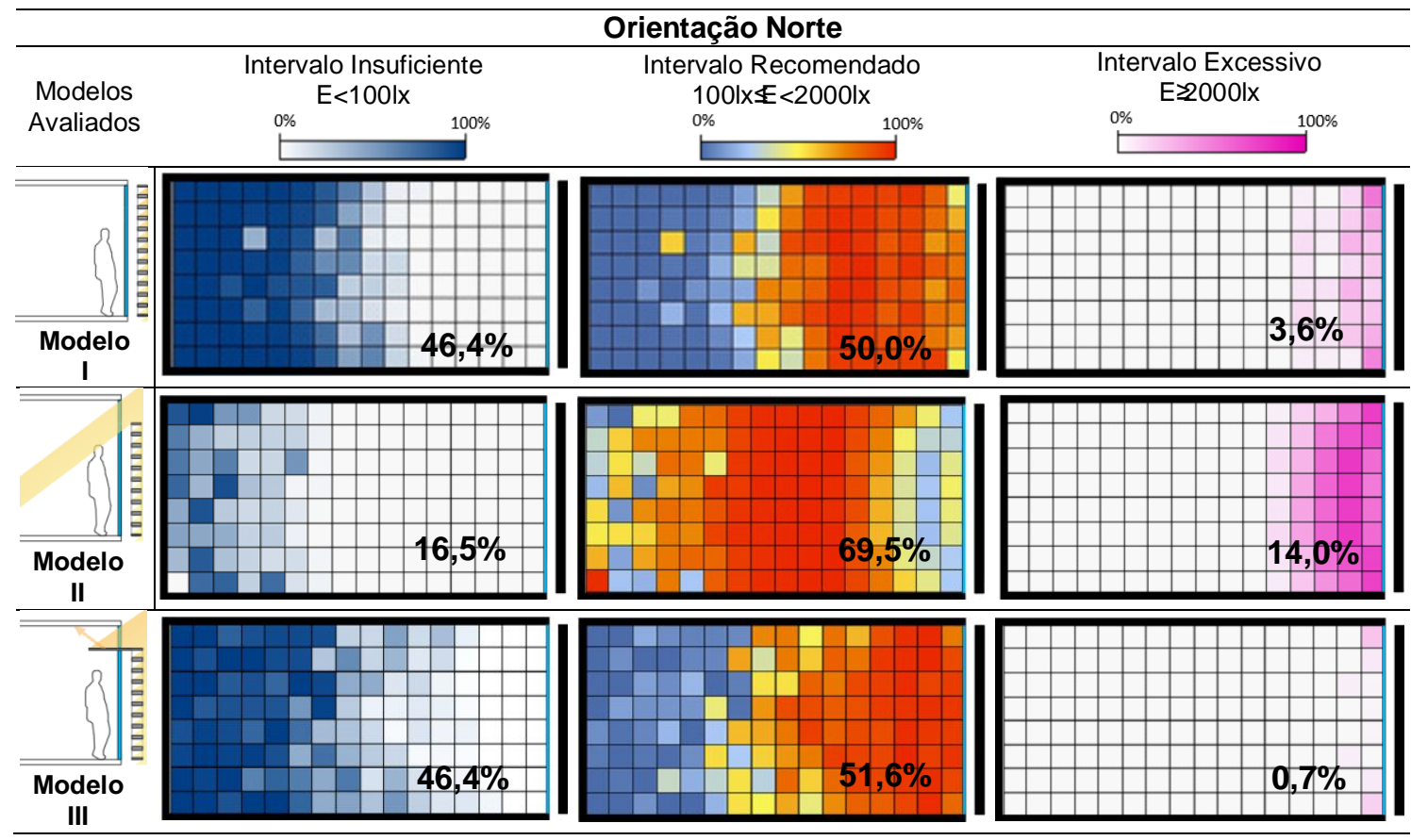




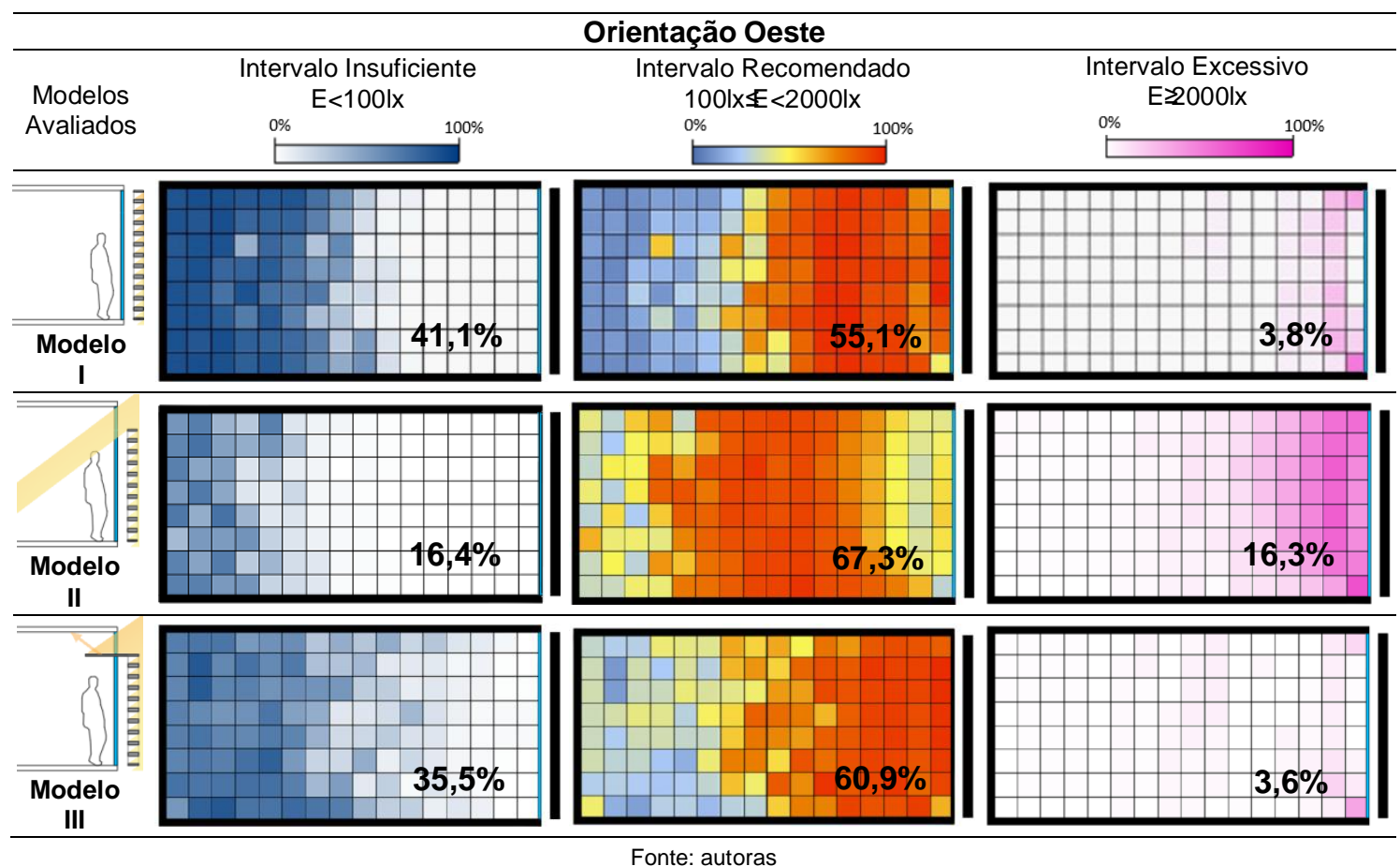

Desta forma, no que se refere aos intervalos da UDI, identifica-se o melhor desempenho com o Modelo III, tendo em vista que esse: reduz a iluminação excessiva de maneira mais significativa, garante mais de $50 \%$ das horas do dia no intervalo recomendado, possibilita para o usuário uma faixa de céu visível em função da janela alta e por fim controla o decaimento da luz natural nos espaços mais profundos do ambiente interno.

Assim, foi realizada uma segunda etapa de avaliação explorando o Modelo III (elemento vazado + janela alta + prateleira de luz). Nas novas versões desse modelo buscou-se potencializar o desempenho do mesmo variando a profundidade interna da prateleira de luz, ainda associada ao elemento vazado e à janela alta.

$\mathrm{Na}$ segunda etapa de avaliação dos intervalos da UDI, como indica a Figura 6, para o intervalo insuficiente $(E<100 \mid x)$ observa-se que o Modelo III10 apresentou o melhor desempenho para as orientações Norte e Oeste, ao compreender os menores percentuais nesse intervalo, inferiores a $30 \%$, enquanto o pior desempenho se deu com o Modelo III70. Isso indica um aumento no desempenho energético da edificação em função da menor demanda por energia elétrica para iluminação artificial.

No que se refere ao intervalo recomendado (100lx $\mathbb{E}<20001 \mathrm{x}$ ), nota-se que todos os modelos avaliados contemplaram mais de $50 \%$ das horas do dia nesse intervalo, destacando a melhor performance com o Modelo III10 para Norte e Modelo III30 para Oeste. Com a utilização desses modelos em suas respectivas orientações só será necessário o acionamento da iluminação artificial em cerca de $30 \%$ das horas do dia.

Em relação ao intervalo excessivo (Eæ2000lx), todos os modelos avaliados nessa etapa apresentaram boa capacidade de reduzir a iluminação excessiva, como menos de $10 \%$ das horas do dia nesse intervalo, onde o melhor desempenho se deu com o Modelo III70.

Nota-se ainda uma diferença de desempenho mais significativa quando os modelos são avaliados na orientação Norte. Esse ganho de performance chega até 1,6 vezes para o intervalo recomendando $(100|x \notin<2000| x)$, por exemplo, enquanto para a orientação Oeste esse valor é de 1,2 vezes. Isso 
evidencia, portanto, uma necessidade de cautela ainda maior na escolha do modelo para a orientação Norte.

Ademais, identifica-se uma relação de que quanto maior a profundidade interna da prateleira de luz associada à janela alta e ao elemento vazado, maior a capacidade de reduzir a iluminação excessiva. Todavia, a maior profundidade interna da prateleira de luz compromete os trechos mais profundos do ambiente interno, ao reduzir a iluminação.

Figura 6: Intervalos da UDI para os modelos avaliados na segunda etapa, orientações Norte e Oeste

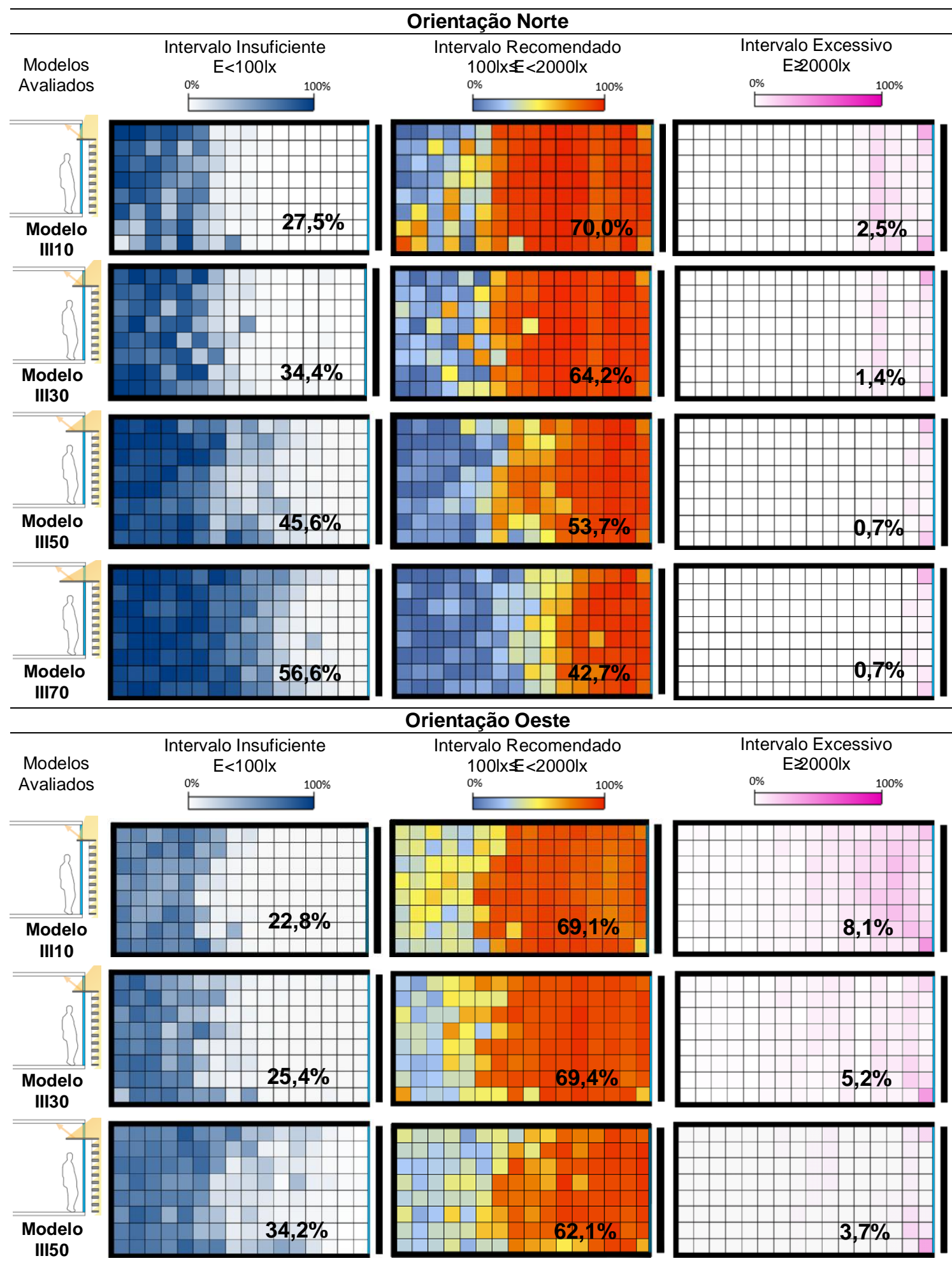




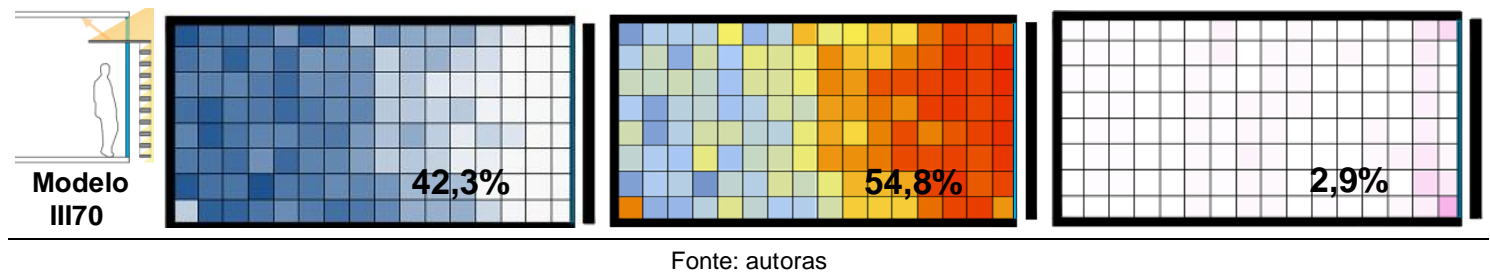

De modo geral, no que se refere à segunda etapa de avaliações dos intervalos da UDI, verifica-se o melhor desempenho do Modelo III10 para a orientação Norte e do Modelo III30 para a orientação Oeste, apesar do desempenho similar ao Modelo III10 para essa orientação. Esses modelos nas suas respectivas orientações conseguiram garantir os maiores percentuais no intervalo recomendado (1001x $\mathbb{E}<20001 \mathrm{x})$, ao mesmo tempo que possibilitaram que o trecho mais profundo do ambiente interno fosse iluminado de forma mais satisfatória. Acrescido a isso, os modelos também garantiram baixos percentuais no intervalo excessivo (Eæ2000lx) na região próxima à abertura.

\subsection{Autonomia da lluminação Natural/Daylight Autonomy (DA)}

Ao analisar a Autonomia da lluminação Natural (DA) para o valor de iluminância previamente determinado de 500lx conforme a NBR ISO/CIE 8995-1 (ABNT, 2013), para as orientações Norte e Oeste, como indica a Figura 7 , observa-se que todos os modelos apresentaram valores de DA inferiores a $50 \%$. Isso indica a necessidade de complementação com iluminação artificial em mais de $50 \%$ das horas do dia para todos os modelos avaliados.

Aparentemente o melhor desempenho se deu com o Modelo II que alcançou os maiores valores de DA, cerca de $40 \%$, para ambas orientações. Todavia, nas avaliações dos intervalos da UDI esse foi o modelo que apresentou os maiores percentuais no intervalo excessivo (Eख2000lx), sendo assim, parte dessa iluminação não poderá ser aproveitada, por estar associada ao ofuscamento e aos contrastes luminosos. Nesse sentido, vale destacar o desempenho do Modelo III10, que apresentou valores de DA superiores a $30 \%$ e ainda garantiu baixos percentuais no intervalo excessivo da UDI (inferiores a $10 \%)$.

O pior desempenho se deu principalmente com os Modelos III, III50 e III70 que alcançaram o valor de DA indicado em menos de $20 \%$ das horas do dia. Isso decorre devido à presença das prateleiras de maiores profundidades internas, que dificultaram o acesso à iluminação adequada principalmente no trecho mais profundo do ambiente interno.

Figura 7: Autonomia da lluminação Natural $\left(\mathrm{DA}_{500}\right)$ para todos os modelos avaliados, orientações Norte e Oeste

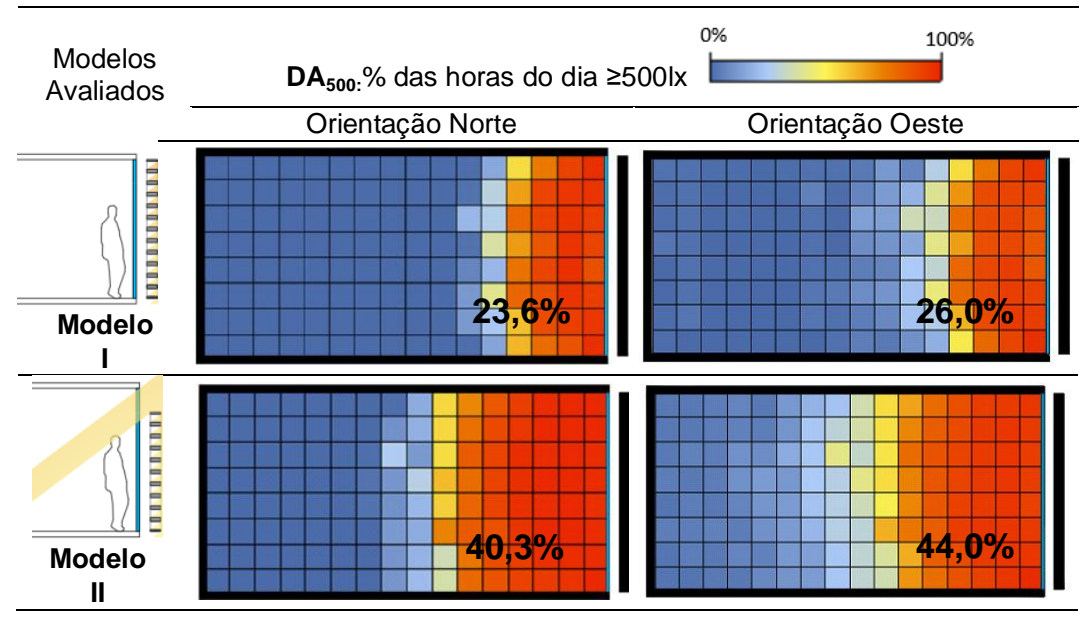




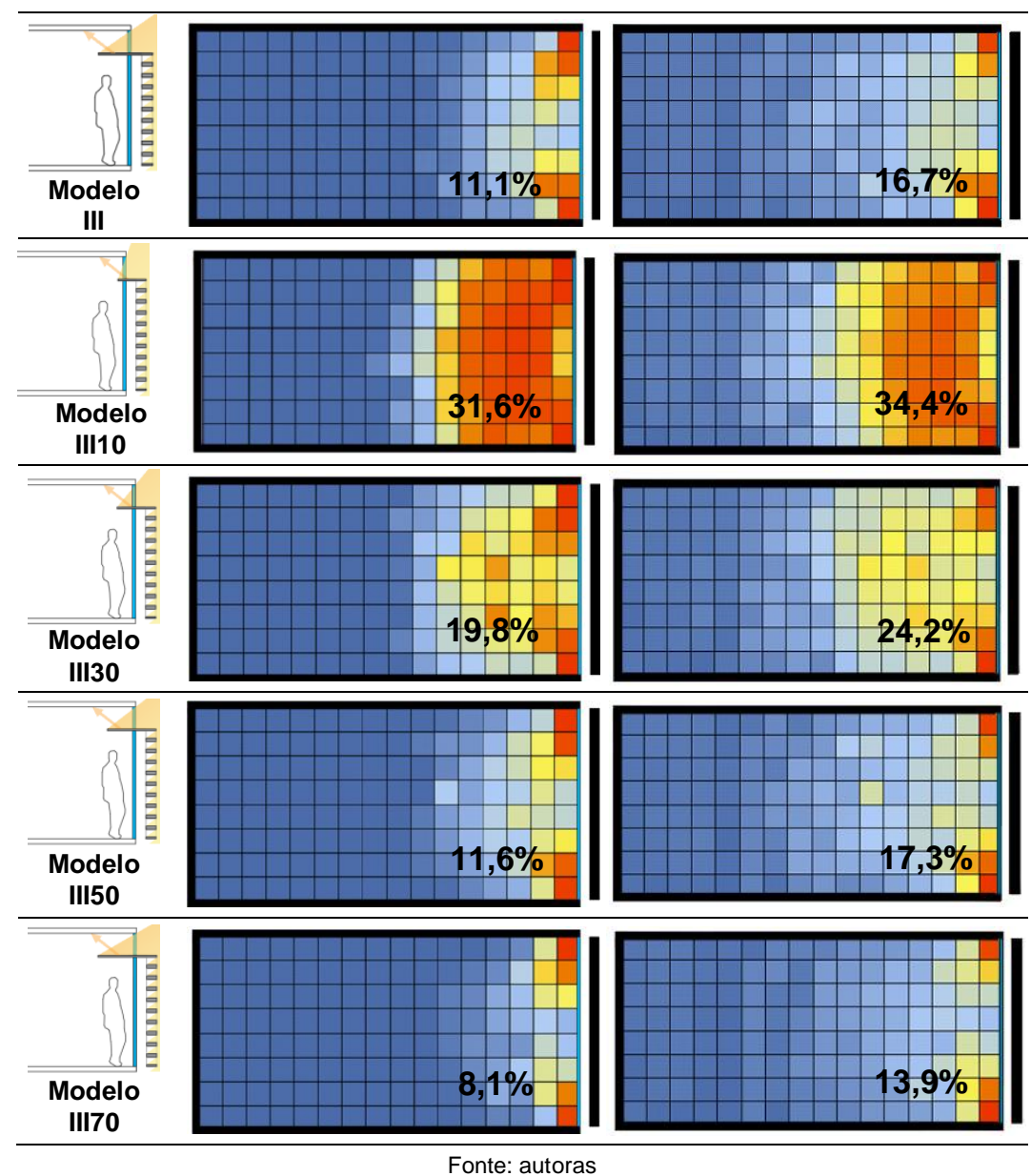

\subsection{Uniformidade}

Ao analisar a Uniformidade para os solstícios de inverno e verão, para as orientações Norte e Oeste, como indica a Figura 8, observa-se que todos os modelos apresentaram índice inferior a 0,3, não alcançando dessa forma o índice mínimo de 0,6 estabelecido pela NBR ISO/CIE 8995-1 (ABNT, 2013). Isso indica que todos os modelos avaliados apresentam elevados contrastes luminosos no ambiente interno.

Os baixos valores de Uniformidade obtidos pelos modelos podem ser atribuídos a dificuldade de os modelos com prateleira de luz (Modelos II, II10, II30, II50, II70) e apenas com elemento vazado (Modelo I) de iluminarem os trechos mais profundos do ambiente interno, apesar da boa capacidade de reduzir a iluminação excessiva próximo à fachada. Somente o modelo com janela alta (Modelo III) apresentou boa capacidade de iluminar os trechos mais profundos, mas admitiu elevados percentuais de iluminação excessiva na região próxima à fachada.

De modo geral, apesar de nenhum modelo atingir o desempenho pretendido, nota-se uma melhora no desempenho com os modelos com prateleira de luz, principalmente aqueles com prateleira de maior profundidade (Modelos II, II50, II70). Todavia, é importante destacar que a melhor performance desses modelos ocorre em função da redução significativa dos valores de iluminância e não por alcançar valores adequados ao longo do ambiente.

Além disso, verifica-se um ganho de performance para todos os modelos quando não há incidência de radiação solar direta, nesse caso para a orientação Norte no solstício de verão, para os períodos da manhã e da tarde, e para a orientação Oeste no período da manhã para os solstícios de inverno e verão. 
Figura 8: Uniformidade para todos os modelos avaliados, para solstícios de inverno e verão, orientações Norte e Oeste

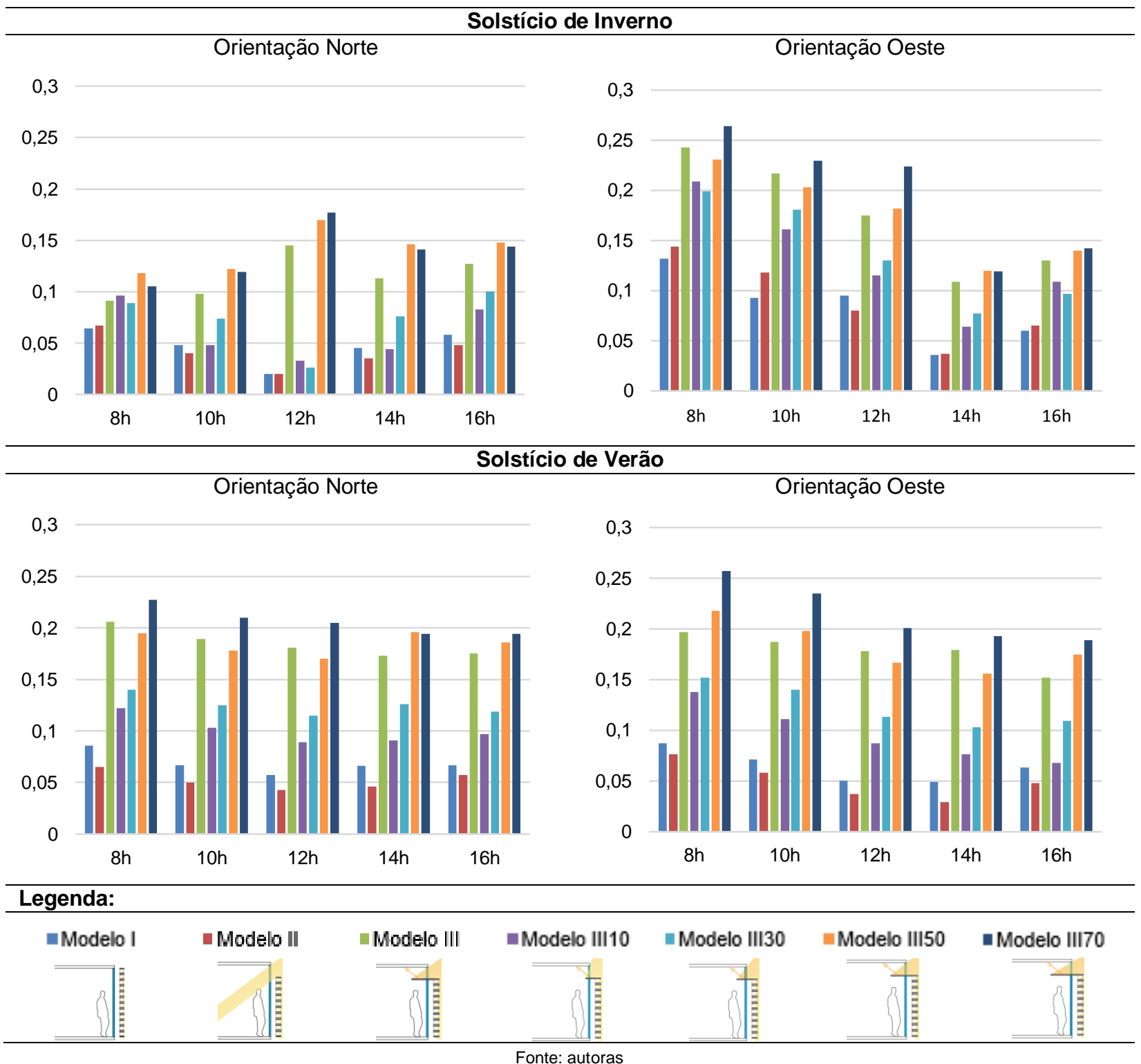

\subsection{Síntese dos Resultados}

O Quadro 1 apresenta a síntese dos resultados relativos aos Intervalos da UDI, à Autonomia da lluminação Natural (DA) e à Uniformidade, para todas as orientações (Norte e Oeste) e modelos avaliados (Modelo I, Modelo II, Modelo III, Modelo III10, Modelo III30, Modelo III50 e Modelo III70). A fim de se facilitar a comparação entre os modelos para todos os critérios analisados, foram estabelecidos parâmetros para a avaliação do desempenho que compreende: desempenho satisfatório, desempenho moderado e desempenho insatisfatório, como consta na legenda. 
Quadro 1: Síntese dos resultados para todos os modelos e parâmetros avaliados

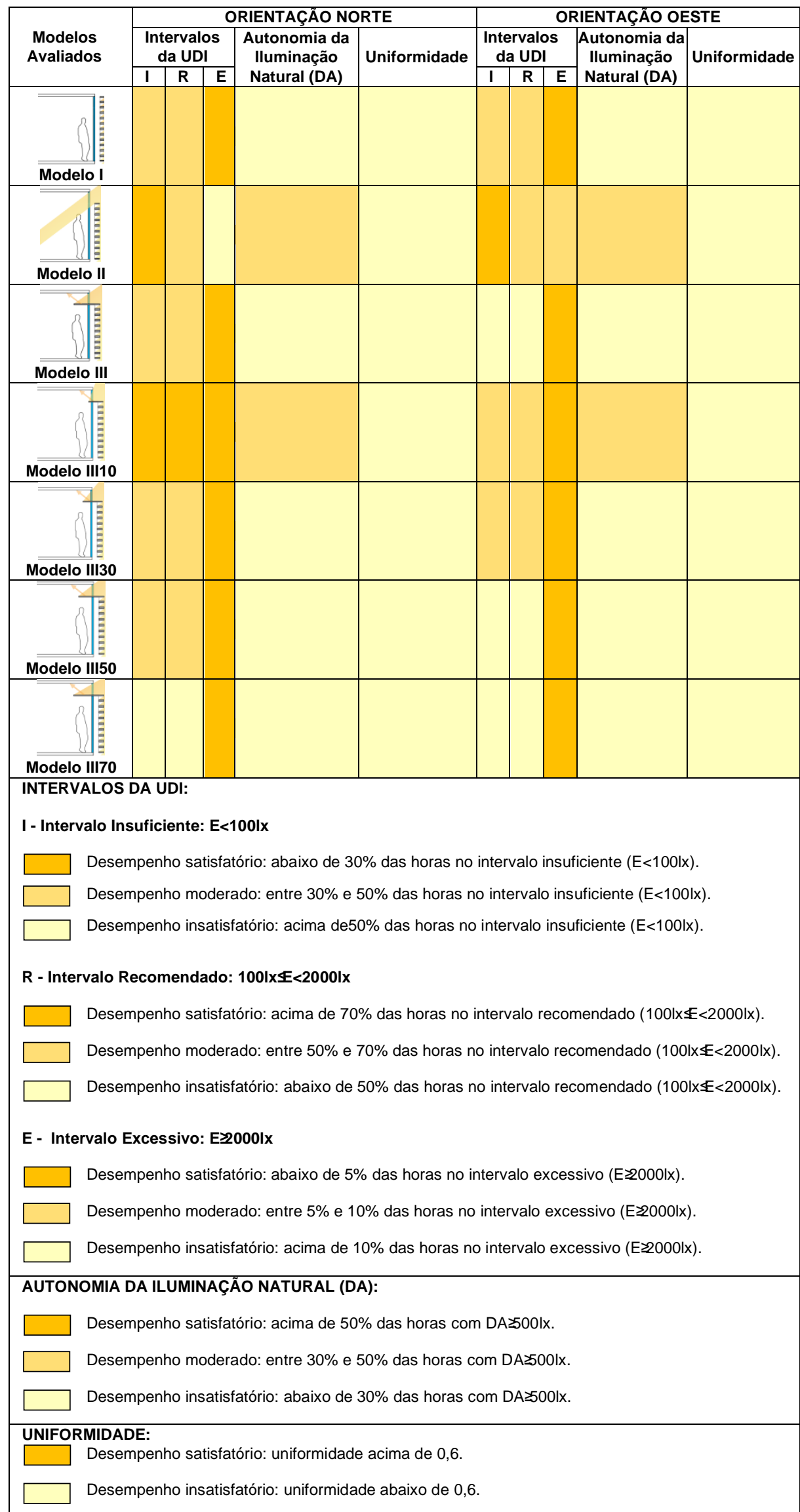

Fonte: autoras 


\section{Conclusão}

Esta pesquisa teve por objetivo investigar a performance luminosa da associação entre elemento vazado, janela alta e prateleira de luz para um ambiente interno de escritório em localidade de clima tropical úmido. Como parâmetros de análises foram adotados os Intervalos da UDI, a Autonomia da lluminação Natural (DA) e a Uniformidade.

A partir das avaliações dos intervalos da UDI identificou-se um melhor desempenho nos modelos com elemento vazado associado à janela alta e à prateleira de luz para as orientações Norte e Oeste. No caso da orientação Norte, essa melhor performance se deu com o Modelo III10, prateleira de luz com profundidade interna de $10 \mathrm{~cm}$, e para a orientação Oeste com o Modelo III30, prateleira de luz com profundidade interna de $30 \mathrm{~cm}$. Esses modelos em suas respectivas orientações conseguiram garantir os maiores percentuais no intervalo recomendado (cerca de $70 \%$ ), bem como manter baixos percentuais no intervalo excessivo no trecho próximo à abertura, sem, contudo, reduzir demasiadamente a iluminação no trecho mais profundo.

Nas avaliações da Autonomia da lluminação Natural (DA) todos os modelos apresentaram dificuldade de alcançar o limite mínimo de 500lx determinado pela NBR ISO/CIE 8995-1 (ABNT, 2013), demandando desta forma complementação com iluminação artificial em mais de $50 \%$ das horas do dia para todas as orientações simuladas. Apesar do Modelo II apresentar o melhor desempenho no que se refere ao DA, cabe lembrar que este modelo também admitiu os maiores percentuais no intervalo excessivo da UDI. Observa-se então que como a DA não estabelece valores máximos de iluminância, esta acaba admitindo valores excessivos, os quais acabam ocasionando ofuscamento e que não necessariamente indicam uma iluminância adequada para a prática de atividades. Assim, para uma análise mais coerente da DA indica-se que essa seja feita associada a outros parâmetros, como os intervalos da UDI, por exemplo.

Em relação à Uniformidade, nenhum dos modelos atingiu o limite mínimo de 0,6 estabelecido pela NBR ISO/CIE 8995-1 (ABNT, 2013), indicando desta forma elevados contrastes luminosos no ambiente interno. Isso é decorrente, no Modelo II, da iluminação excessiva admitida no trecho próximo à fachada. Já nos demais Modelos (I, III, III10, III30, III50, III70) se dá em função da dificuldade de iluminar o trecho mais profundo do ambiente interno.

Observa-se ainda para as orientações analisadas (Norte e Oeste) uma relação de que, quanto maior a profundidade interna da prateleira de luz combinada com janela alta e elemento vazado, maior a capacidade de reduzir a iluminação excessiva, todavia maior será a dificuldade de iluminar a região mais profunda do ambiente interno.

Por fim, a sequência metodológica apresentada é aplicável a outros modelos e localidades, desde que sejam levadas em consideração suas particularidades. Como limitações da proposta, as avaliações foram efetuadas apenas para as orientações Norte e Oeste, sendo indicado que sejam realizadas para as demais orientações. Além disso, as análises dos intervalos da UDI e da DA são feitas para médias anuais, assim o desempenho dos modelos para dias e horários específicos poderá sofrer influência da trajetória solar.

\section{Agradecimentos}

As autoras agradecem à Coordenação de Aperfeiçoamento de Pessoal de Nível Superior (CAPES) pelo apoio financeiro. 


\section{Referências}

ABNT ASSOCIAÇÃO BRASILEIRA DE NORMAS TÉCNICAS. NBR 15215-4. Iluminação natural: verificação experimental das condições de iluminação interna de edificações: método de medição. Rio de Janeiro, 2005.

ASSOCIAÇÃO BRASILEIRA DE NORMAS TÉCNICAS (ABNT). NBR ISO/CIE 8995-1. Iluminação de ambientes de trabalho - Parte 1: interior. Rio de Janeiro: ABNT, 2013.

BAKER, N.; FANCHIOTTI, A.; STEEMERS, K. Daylighting in Architecture - A European Reference Book. London: EarthscanLtd. 2010.

BOLSSONI, G.; LARANJA, A. Análise do desempenho lumínico de ambientes internos a partir da atuação de elementos vazados. XV Encontro Nacional de Conforto no Ambiente Construído (ENCAC) e XI Encontro Latino-Americano de Conforto no Ambiente Construído (ELACAC). João Pessoa, 2019a.

BOLSSONI, G.; LARANJA, A. A Influência da Refletância dos Elementos Vazados no Desempenho Lumínico. II Congesso Internacional de Arquitetura e Cidade (ARQCIDADE) e X Coletânea ARQURB. Vila Velha, 2019b.

CARTANA, R.; PEREIRA, F. MAYER, A. Estudo piloto para elementos de controle solar desenvolvidos com modelagem paramétrica e fabricação digital. Ambiente Construído, v. 18, n. 3, p. 67-82, Porto Alegre, 2018.

CHING, F. D. K. Dicionário visual de arquitetura. São Paulo: Martins Fontes, 2010.

FIGUEIRÓ, M. A Luz e a Sua Relação Com a Saúde. Lume, São Paulo, v. 8, n. 44, jun. 2010.

FREEWAN, A. A. Maximizing the light shelf performance by interaction between lightshelf geometries and curved ceiling. Energy Conversion and Management, n.51, p.1600-1604, 2010.

FREEWAN, A. A. Y. Impact of external shading devices on thermal and daylighting performance of offices in hot climate regions. Solar Energy, v.102, p. 14-30, 2014.

GONÇALVES, J.; VIANA, N.; MOURA, N. Iluminação Natural e Artificial. Procel Edifica. Rio de Janeiro, 2011.

LAMBERTS, R.; DUTRA, L.; PEREIRA, F. O. R. Eficiência energética na arquitetura. $3^{a}$ ed. São Paulo, 2014.

LAMBERTS, R.; GHISI, R.; RAMOS, G. Impactos da adequação climática sobre a eficiência energética e o conforto térmico de edifícios de escritórios no Brasil. 49p. Florianópolis: LABEEE, 2006.

MAIOLI, R. Avaliação da influência do dispositivo prateleira de luz no conforto visual em edificação comercial com entorno obstruído. Dissertação (Mestrado) - Programa de PósGraduação em Engenharia Civil, Universidade Federal do Espírito Santo, Vitória, 2014.

MARTAU, B. T. A Luz Além da Visão. Lume, v. 7, n. 38, jun. 2009.

MESA, N. A.; CORICA, L.; PATTINI, A. Evaluation of the potential of natural light to illuminate buildings in dense urban environment. A study in Mendoza, Argentina. Renewable Energy, n. 36, p. 2414-2423, 2011.

NABIL, A.; MARDALJEVIC, J. Useful daylight illuminances: A replacement for daylight factors. Energy and Buildings, London: Elsevier, v.38, p. 905 - 913, 2006. 
OCHOA, Carlos Ernesto; CAPELUTO, Isaac Guedi. Evaluating visual comfort and performance of three natural lighting systems for deep office buildings in highly luminous climates. Building and Environment, v. 41, n. 8, p. 1128-1135, ago. 2006.

RAPHAEL, B. Active control of daylighting features in buildings. Computer-Aided Civil and Infrastructure Engineering, n.26, p.393-405, 2011.

REINHART, C. F.; WIENOLD, J. The Daylighting Dashboard: A Simulation-based Design Analysis for Daylit Spaces. Building and Environment, v. 46, n. 2, p. 386-396, 2011.

SANTOS, A. J. A lluminação nos Edifícios: Uma perspectiva no âmbito do conforto ambiental e da eficiência energética. 1a ed. Lisboa: LNEC, 2014.

VITÓRIA. Lei $n^{\circ}$. 4821, de 30 de dezembro de 1998. Código de Edificações do Município de Vitória. Vitória, 1998. Disponível em: <https://leismunicipais.com.br/codigo-de-obras-vitoria-es> Acesso em: 17 out. 2019.

\section{GABRIELA DA CONCEIÇÃO BOLSSONI}

Possui graduação em Arquitetura e Urbanismo pela Universidade Federal do Espírito Santo (2018). Atualmente, é Mestranda do Programa de Pós-Graduação em Arquitetura pela Universidade Federal do Espírito Santo. Membro do Laboratório de Planejamento e Projetos - LPP (UFES), onde desenvolve pesquisas principalmente no âmbito da iluminação natural.

Contribuição de coautoria: Contribuiu ativamente na concepção e redação do texto, desde a fundamentação teórica a análise dos resultados. Além disso, foi responsável pelas simulações computacionais, tratamento e apresentação dos dados, bem como elaboração das demais ilustrações apresentadas no artigo.

\section{ANDRÉA COELHO LARANJA}

Possui graduação em Arquitetura e Urbanismo pela Universidade Federal do Espírito Santo (1995), mestrado em Arquitetura pela Universidade Federal do Rio de Janeiro (2000), doutorado em Ciências em Arquitetura pela Universidade Federal do Rio de Janeiro (2010). Atualmente é professora adjunta da Universidade Federal do Espírito Santo no curso de Arquitetura e Urbanismo. Tem experiência na área de Arquitetura e Urbanismo, com ênfase em conforto ambiental, atuando principalmente nos seguintes temas: eficiência energética, arquitetura bioclimática, iluminação natural e ergonomia.

Contribuição de coautoria: Auxiliou em todas as etapas de produção do artigo, desde a fundamentação teórica à análise dos resultados, tendo contribuição fundamental na revisão do texto.

Como citar: BOLSSONI, G.C., LARANJA, A.C. Performance luminosa da associação entre elemento vazado, janela alta e prateleira de luz. Revista Paranoá. n.19, jan/jun de 2021. DOI: http://doi.org/10.18830/issn.1679-0944.n29.2021.11

Editores responsáveis: Daniel Richard Sant'Ana e Caio Frederico e Silva 